\title{
Fragility and Resilience Curves of an Urbanised Sector in the District of Naples
}

\author{
Antonio Formisano *, Nicola Chieffo ** and Marius Mosoarca ** \\ * University of Naples "Federico II" Piazzale Tecchio Naples (Italy) \\ ** Universitatea Politehnica Timisoara Traian Lalescu Street, Timisoara (Romania)
}

\begin{abstract}
In the current paper, the RISK-UE quick method for vulnerability evaluation of an urban sector of Marigliano, a municipality in the district of Naples, has been applied. This paper aims at defining, starting from the seismic vulnerability analysis of the urban area analysed, a method to investigateits urban resilience by developing appropriate behaviouralcurves, that describe the attitude of the urban system to recover from possible seismic events that should occur in the inspected site.

The vulnerability analysis results showed that for modest seismic intensities, buildings show a very slight damage level, whereas for high grade earthquakes almost all buildings should collapse. Moreover, from resilience analyses, it is noticed that the resilience probability expected values for typological classes of the investigated sector tend to decrease especially for buildings made of low-quality masonry.
\end{abstract}

Keywords: Historic centres, seismic vulnerability, damage scenarios, fragility curves, resilience curves.

\section{The Historical Centre of Marigliano}

The town of Marigliano (Figure 1) is a centre of $22.6 \mathrm{~km}^{2}$, located 30 meters above sea level approximately $27 \mathrm{Km}$ far from Naples. The urban layout of the town centre still keeps unchanged the original appearance, generated by a Roman military castrum, with its network of decumani orthogonal to each other. Until the middle ' 800 , the walls and the four city gateways, coinciding with the cardinal points, were still visible.
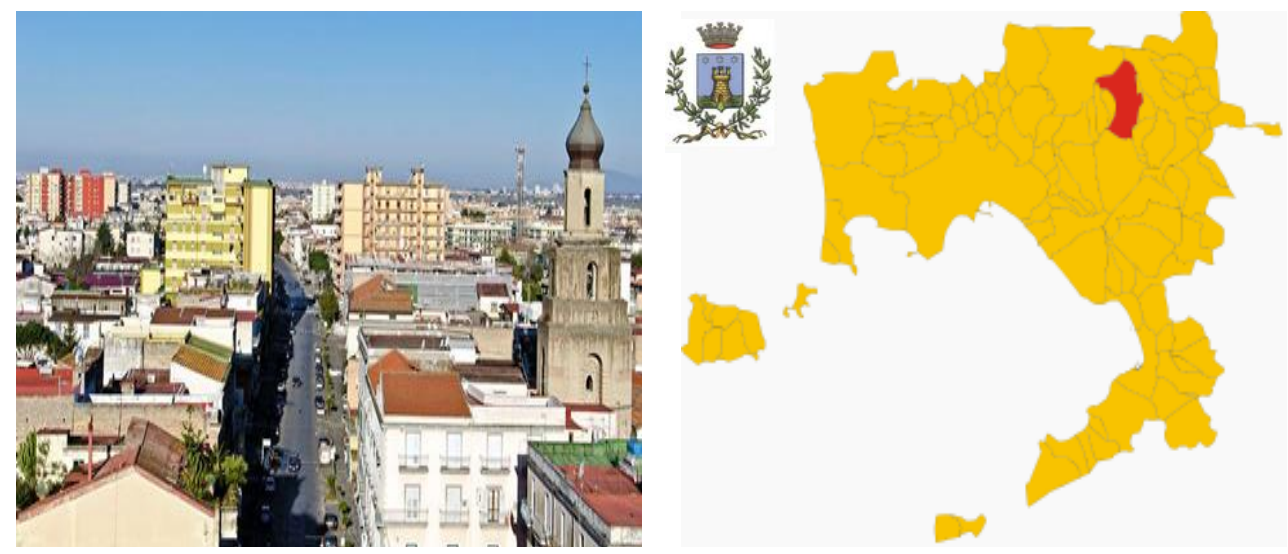

Figure1. The city of Marigliano in the Campania region of Italy

Giannone street, one of the most important road in the antiquity, known as the ancient Cardo Maximus military camp, continues to perform its function of "Via Principalis" of the city, it being marked by some of the most significant buildings, such as the Collegiate complex, the church of San Biagio and the Purgatorio church.

Among the monumental architectures located in the city, a noteworthy place is occupied by the palaces. In particular, the Nicotera palace, an interesting complex born from the unification of most Eighteenth Century buildings into a single aristocratic residence, the Cesarano palace, which still retains all the learned pattern of the Eighteenth Century, and the palace called "DelleOrnie Catalane" have remarkable importance. 
Marigliano belonged to the seismic risk zone 2 according the seismic hazard classification (from 1 the highest to 4 the lowest) given by the Italian Ordinance of the Ministers Council President n. 3274/2003 and updated with the Resolution of the Campania Regional Council n. 5447/2002. Actually, since the seismic hazard of Italy is not more defined through four seismic zones, but with a more precise evaluation of the earthquake intensity based on a grid of $5 \mathrm{Km}^{2} \times 5 \mathrm{Km}^{2}$ covering the whole Italian territory, Marigliano can be considered as a medium-high seismic zone with PGA of $0.176 \mathrm{~g}$ for ordinary constructions at the Life Safety limit state.

\section{The RiSK-UE Method}

The RISK-UE methodology is based on the inventory of elements at risk, whose analysis in terms of their value and vulnerability is made in order to identify the weak points of urban systems. This method was developed into the European homonym project "An advanced approach to earthquake risk scenarios with applications to different European towns", which was applied to seven European cities, namely Barcelona (Spain), Bitola (Macedonia), Bucharest (Romania), Catania (Italy), Nice (France), Sofia (Bulgaria) and Thessaloniki (Greece), in order to reduce losses caused by earthquake and generate action plans for seismic risk mitigation. It is based on a macro seismic approach, where the seismic vulnerability is computed through an appropriate vulnerability index, attributed on a typological basis, which can be changed considering modifier factors in terms of both a regional vulnerability parameter and distinct structural peculiar features. In the method different categories of buildings are grouped into specific classes, assembled within the Building Typology Matrix (BTM), which the typological vulnerability index $V_{\mathrm{I}}$ for each building type is assigned to.

In the current paper the RISK-UE method has been applied to an urban sector of the Marigliano historical centre. According to this method, masonry buildings have been grouped into typological classes. In particular, the investigated sector is composed by 104 buildings (Figure 2): 68 M3.3 class masonry structures with composite steel - reinforced concrete floors (65\% of the built-up); 26 M3.4 class masonry structures with rc floors (25\% of the built-up); 7 M3.1 class masonry structures with timber floors ( $7 \%$ of the built-up); $1 \mathrm{RC} 1$ class reinforced concrete frame (1\% of the built-up) and 2 non-residential buildings ( $2 \%$ of the built-up).

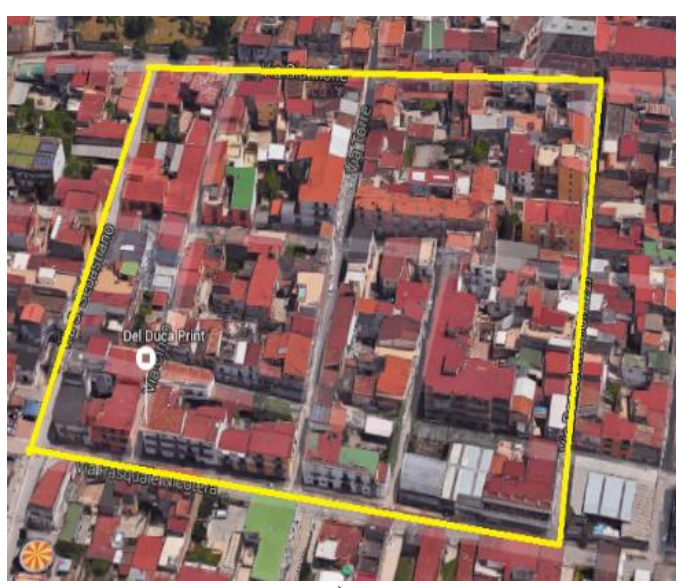

a)

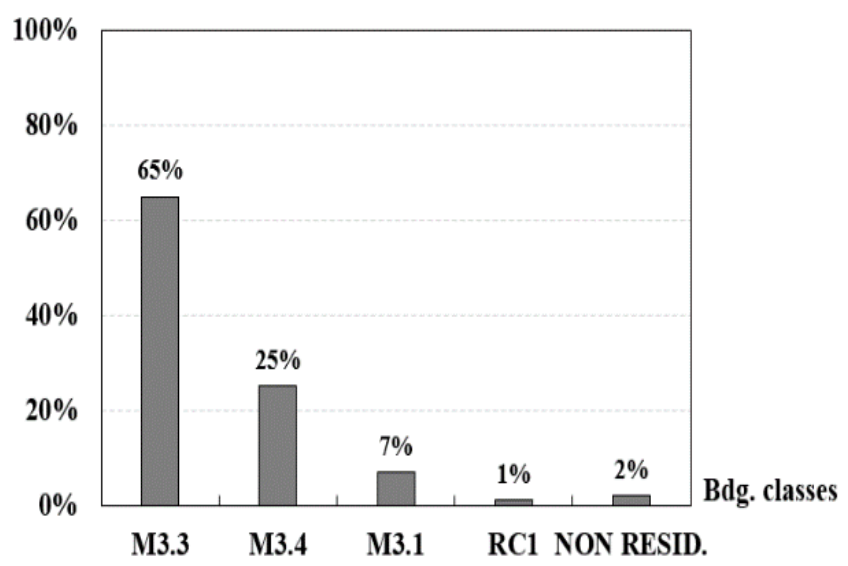

b)

Figure2. Urban sector (a) and typological classes of buildings (b) within the historical centre of Marigliano

The Damage Probability Matrices(DPM) express the occurrence probability of a certain damage level of different typological classes for diverse seismic intensity levels. They can be generated by referring to a generic damage scale expressed in terms of costs (such as the ratio of the repairing cost over the reconstruction one), which can be intended either in phenomenological terms or according to a qualitative estimation of the different damage degree that buildings may undergo. From the practical point of view, DPM can be constructed after binomial coefficients are known. In the examined case, reference has been done to the study developed by the GNDT SSN-2002 working group[13], who found binomial coefficients from statistical analysis of the damages suffered by the various building types under the occurred earthquakes (Figure 3). 

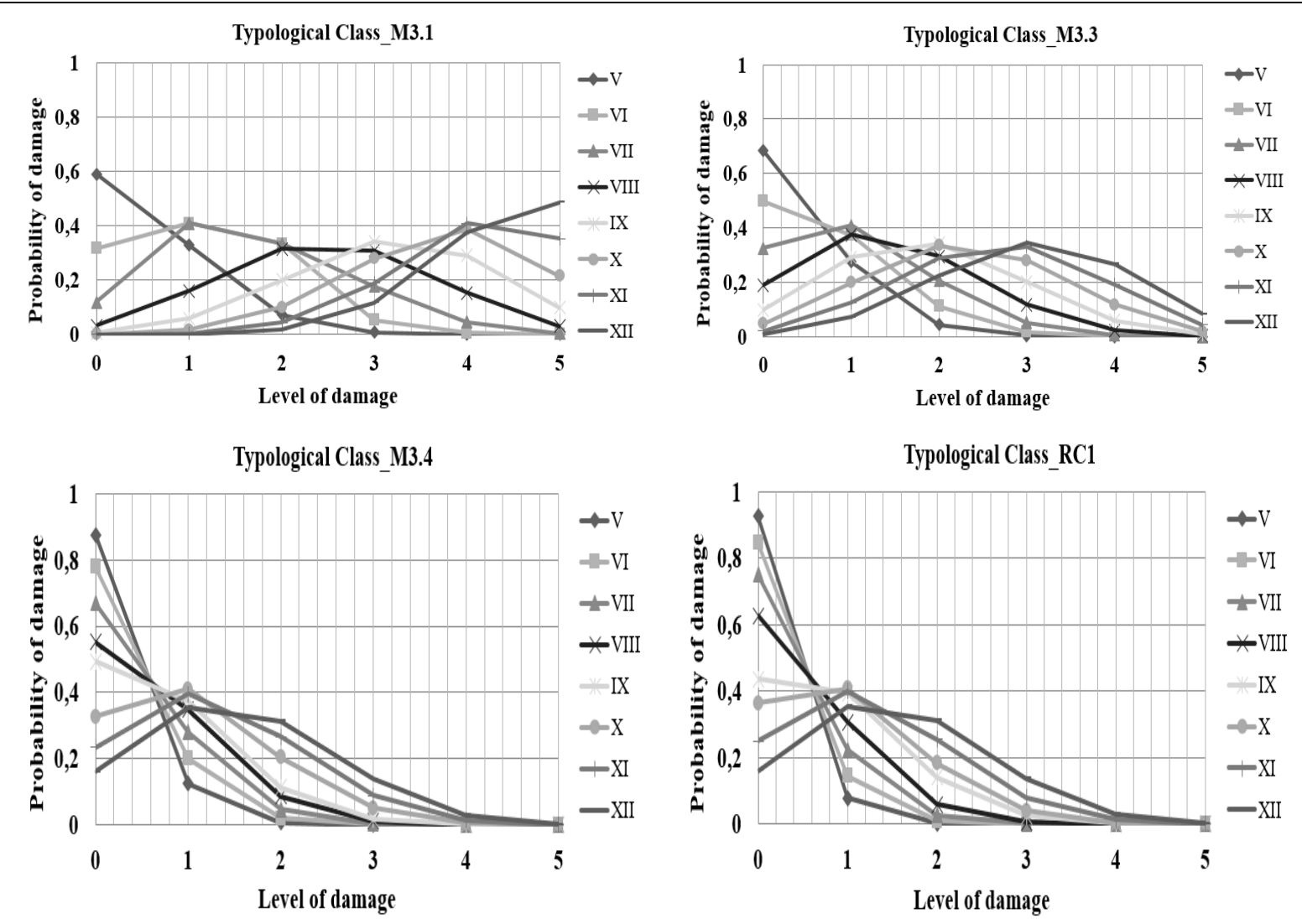

Figure3. Damage Probability Matrix for the building classes within the urban sector of Marigliano.

From the above curves, the binomial distribution is achieved, it corresponding to the conditional probability of having a certain damage threshold $\left(D_{\mathrm{i}}\right)$ differentiated as a function of the macro seismic intensity $\left(S_{\mathrm{I}}\right)$.The distribution of the binomial coefficients in Figure 4 shows how the damage degree for different structure types herein examined tends to growth with increasing of the macro seismic intensity.

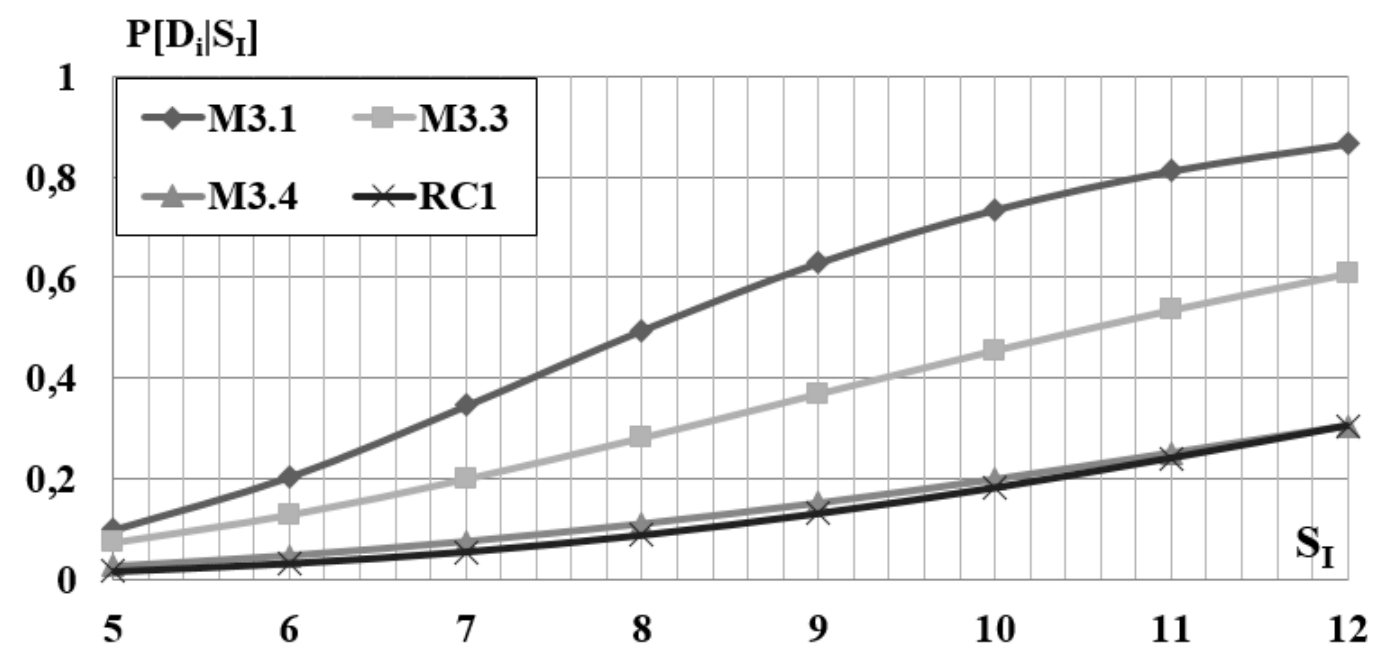

Figure4. Distribution of binomial coefficients for the inspected building classes

As it is shown in Figure 4, the binomial distribution has the highest values for the M3.1 typological class, that is the worst one, after followed by the M3.3 class, where as significantly reduced values, very similar to each other, are noticed for the M3.4 and RC1 classes, which exhibit the best seismic performances. Based on these premises, the vulnerability of the urban sector has been computed according to the RISK-UE method, so obtaining the results of Figure 5, where the building vulnerability rankings for the worst typological classes (M3.3 and M3.4) are shown. 

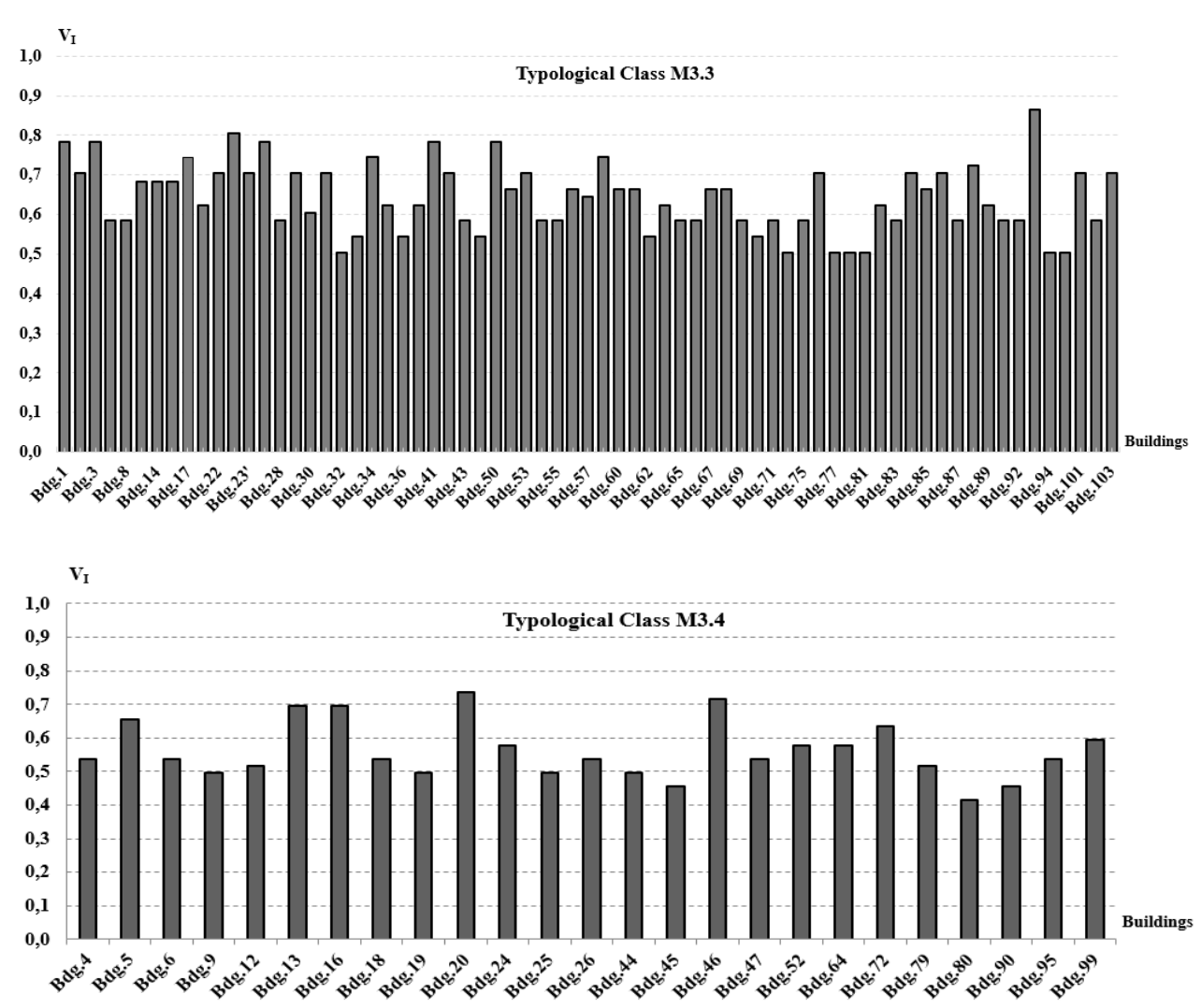

b)

Figure5. Ranking of buildings belonging to M3.3 (a) and M3.4 (b) typological classes.

In particular, it is possible to notice that the most vulnerable building of the typological class M3.3 is the number 93, which has $V_{\mathrm{I}}=0.864$. On the other hand, for the typological class M3.4 the buildings having the highest vulnerability are those with numbers 20 and 46, with indexes equal to 0.736 and 0.716 , respectively. These buildings, composed of tuff stones, have an irregular configuration, both in plan and in elevation, and are not in very good physical conditions (Figure 6).
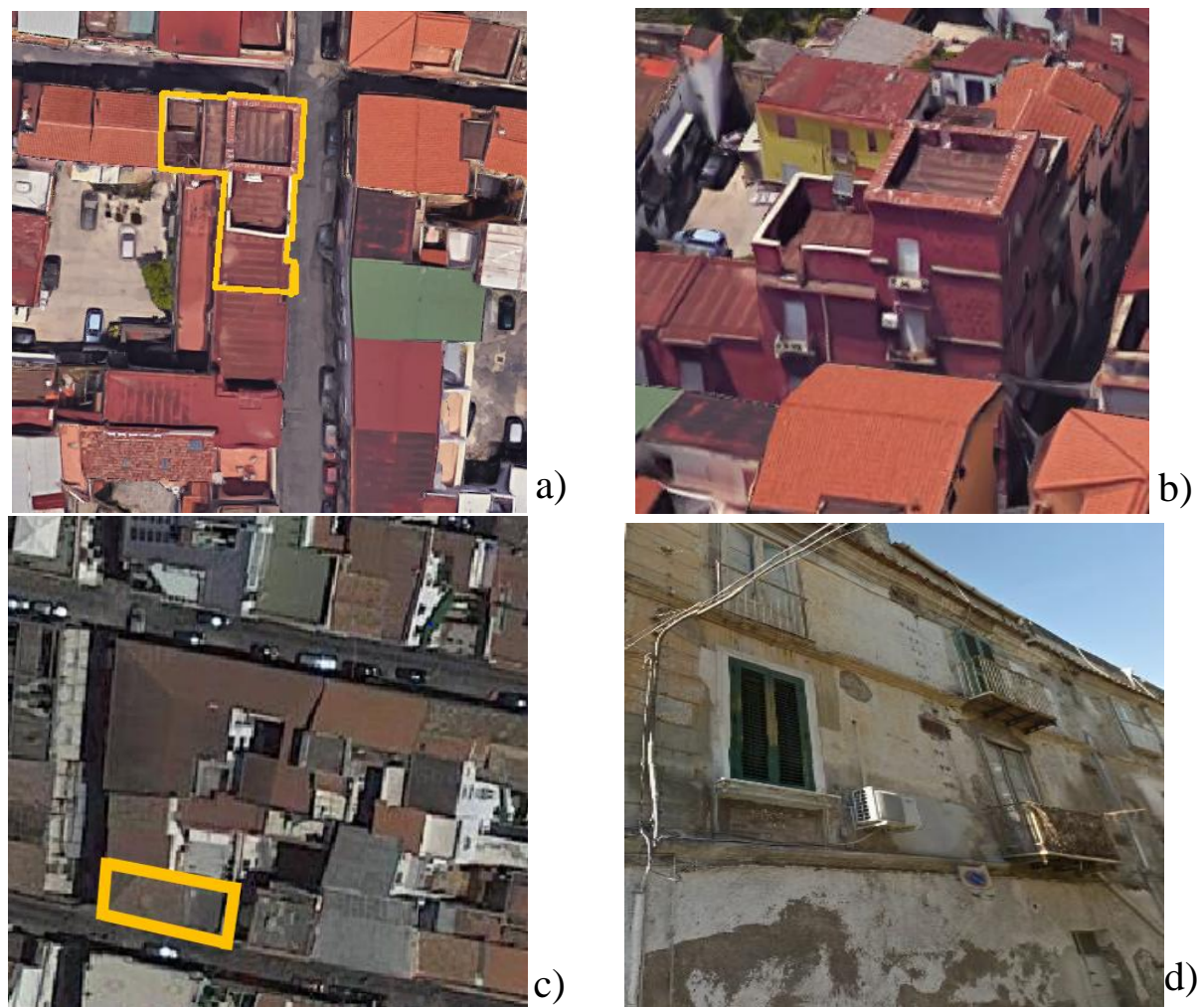

Figure6. Bird eye (a) and $3 D(b)$ views of the building n.93; plan configuration (c) and main facade $(d)$ of the building n. 20. 


\section{The Damage Scenario}

In order to assess the damages should be suffered by building aggregates under different earthquakes, the methodology proposed by Lagomarsino and Giovinazzi[5] has been used.

It is based on the definition of the average damage degree $\mu_{\mathrm{D}}$, a parameter variable between zero and five, where the minimum value and the maximum one represent, respectively, absence of damage and the building collapse. In the case under study, by varying the macro seismic grade $I$ from 5 to 12 , the average damage degree of inspected masonry building compounds has been gotten starting from the vulnerability indexes calculated in the Section 2.

The fragility curves shown in Figure 7 aim at estimating the collapse probability of every typological classes analysed when they are subjected to seismic actions with different intensities. More in detail, the fragility curve can be properly defined as the probability $\mathrm{P}[\mathrm{SL} \mid \mathrm{I}]$ that a building reaches a certain limit state "SL" for a given seismic intensity "I".

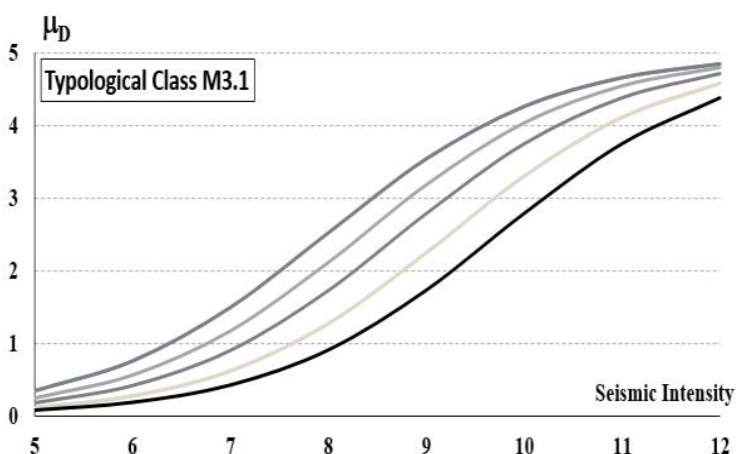

a)

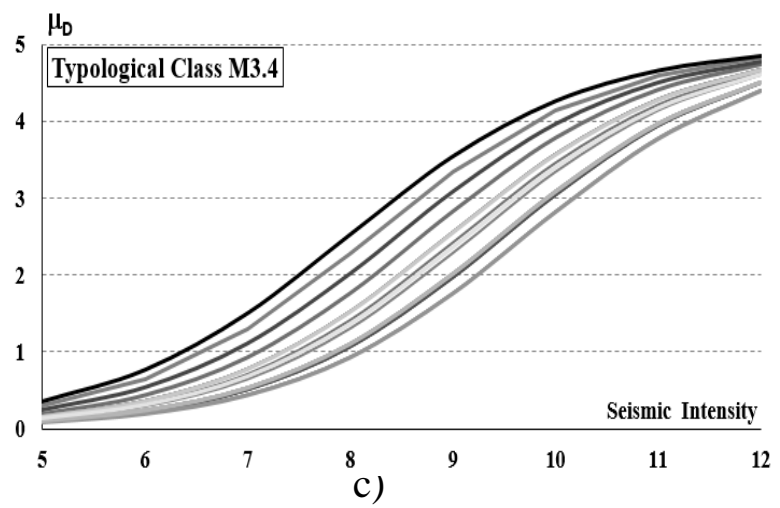

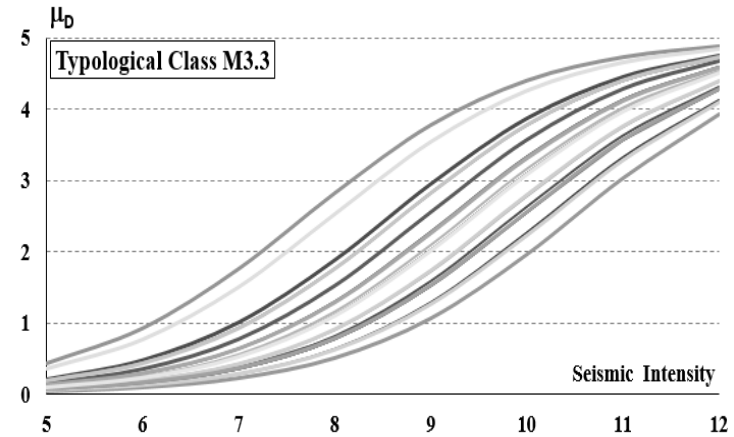

b)

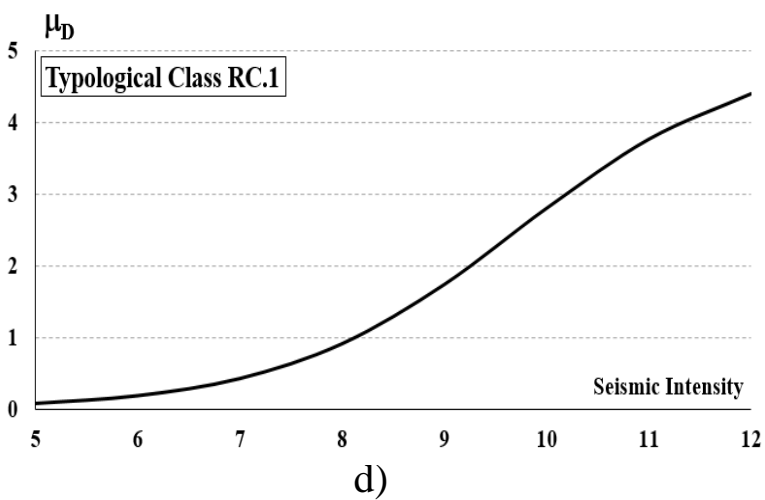

Figure7. Fragility curves for building compounds of the M3.1 (a), M3.3 (b), M3.4 (c) and RC.1 (d) typological classes.

It is possible to perceive that, when the macro seismic intensity tends to increase, the damage level increases as well. Moreover, for the sake of example, if a low seismic intensity $(I=6)$ is considered for both typological classes, the damage increment for the M3.3 typological class is greater than that of the M3.4 building class. In fact, since for the M3.3 class, $\mu_{\mathrm{D}}=0.91$, while for the M3.4 class $\mu_{\mathrm{D}}=$ 0.76 , a damage increase of about $19 \%$ is noticed for the former class of buildings. Contrary, for high values of the seismic intensity ( $I>9)$, the fragility curves of the two building classes follow more or less the same trend.

Starting from the above fragility curves, a seismic damage scenario characterizing the historical centre of Marigliano has been derived.

Considering the representative damage parameter $\mu_{\mathrm{D}}$, which is defined in the EMS-98 scale, the expected number of buildings that undergo a certain damage level has been determined. So, for the representation of the damage map, five ranges of average damage degrees have been considered, as shown in Table 1. 
Antonio Formisano et al.

Table1. Ranges of values assumed by the average damage degree $\mu_{D}$.

\begin{tabular}{|c|c|}
\hline$\mu_{\mathrm{D}}$ & Level of damage \\
\hline $0-1$ & No damage \\
\hline $1-2$ & Moderate damage \\
\hline $2-3$ & Serious damage \\
\hline $3-4$ & Very serious damage \\
\hline $4-5$ & Collapse \\
\hline
\end{tabular}

In the case study, the parameter $\mu_{\mathrm{D}}$ has been calculated by varying the macro-seismic intensity from VII to XII, in order to elaborate a probable scenario of the entire urban sector. Damage maps have been herein reported for three different seismic intensity levels $I$ equal to 7, 9 and 12. Starting from a seismic intensity $I=7$, where damage is moderate or absent, to $I=9$, it is possible to notice the diffused presence of buildings with significant and very serious damages, while only $30 \%$ of total buildings show moderate damages. On the other hand, for $I=12$ the collapse of all buildings in the area of interest is recorded (Figure 8).
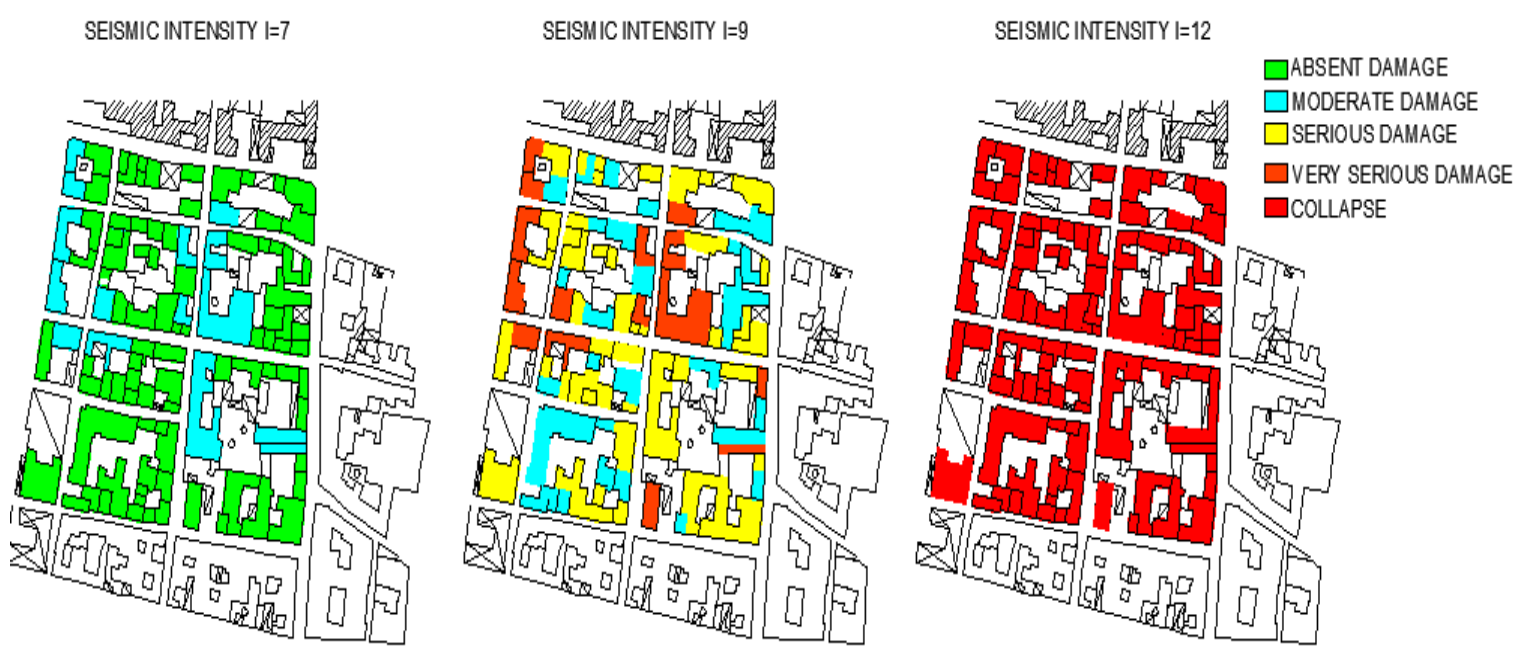

Figure8. Damage scenarios of the investigated sector within the historical centre of Marigliano

\section{URbAN SEISMIC FragILITY AND RESILIENCE}

In order to evaluate the seismic behaviour of the investigated sector, fragility curves for all building class types have been determined by associating to each earthquake intensity level the probability of attaining a given damage. For simplicity, the classes of buildings analysed have been called with letters from $A$ to $D$ according to the classification of Dolce and Zuccaro[13]. Particularly, M3.1 and M3.3 typological classes have been indicated with letters $A$ and $B$, respectively. Instead, $C$ and $D$ have been used to represent, respectively, the M3.4 and RC1 typological classes. According to this classification, it is apparent that class A buildings are the most vulnerable constructions, while class D buildings have a good behaviour under seismic action.

Aiming at having a better representation of such curves also for mechanical analyses, the macroseismic intensity can be transformed into peak ground acceleration $a_{\mathrm{g}}$ through appropriate correlation formulas. In literature there are different formulations that put in relationship the seismic intensity with the spectral acceleration. However, only the two laws proposed by Guagenti and Petrinihave been used in the present study in order to define the fragility curves of the investigated area.

From these curves it is possible to assess the damage probability, calculated as the difference of the cumulative probability for each value of $a_{\mathrm{g}}$, to reach or exceed the states of the subsequent damage (Figure 9).From this figure it is clear that, as the damage level is increased, the probability to accomplish or overpass an assigned level of damage for a given seismic acceleration is progressively reduced. 

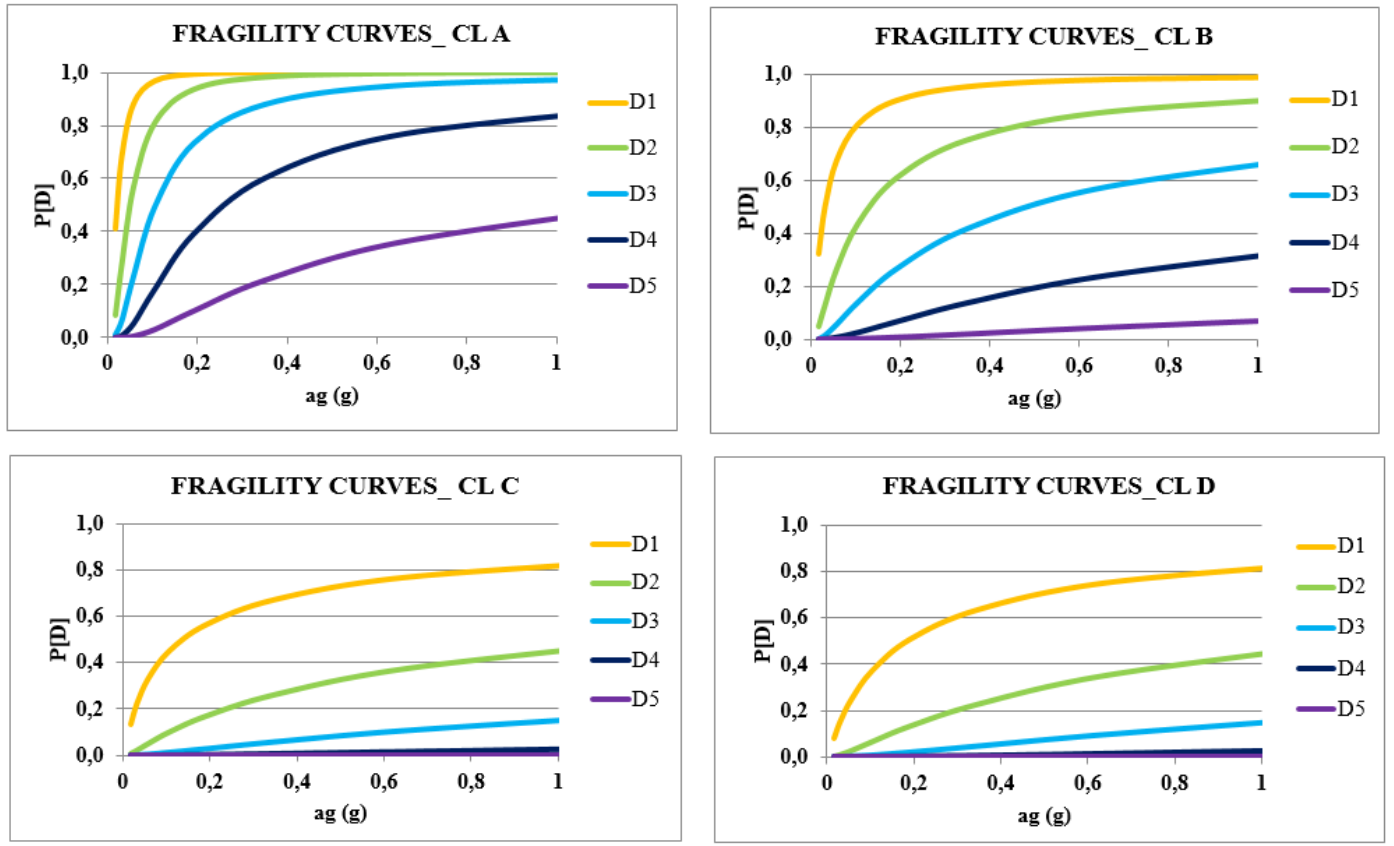

a)
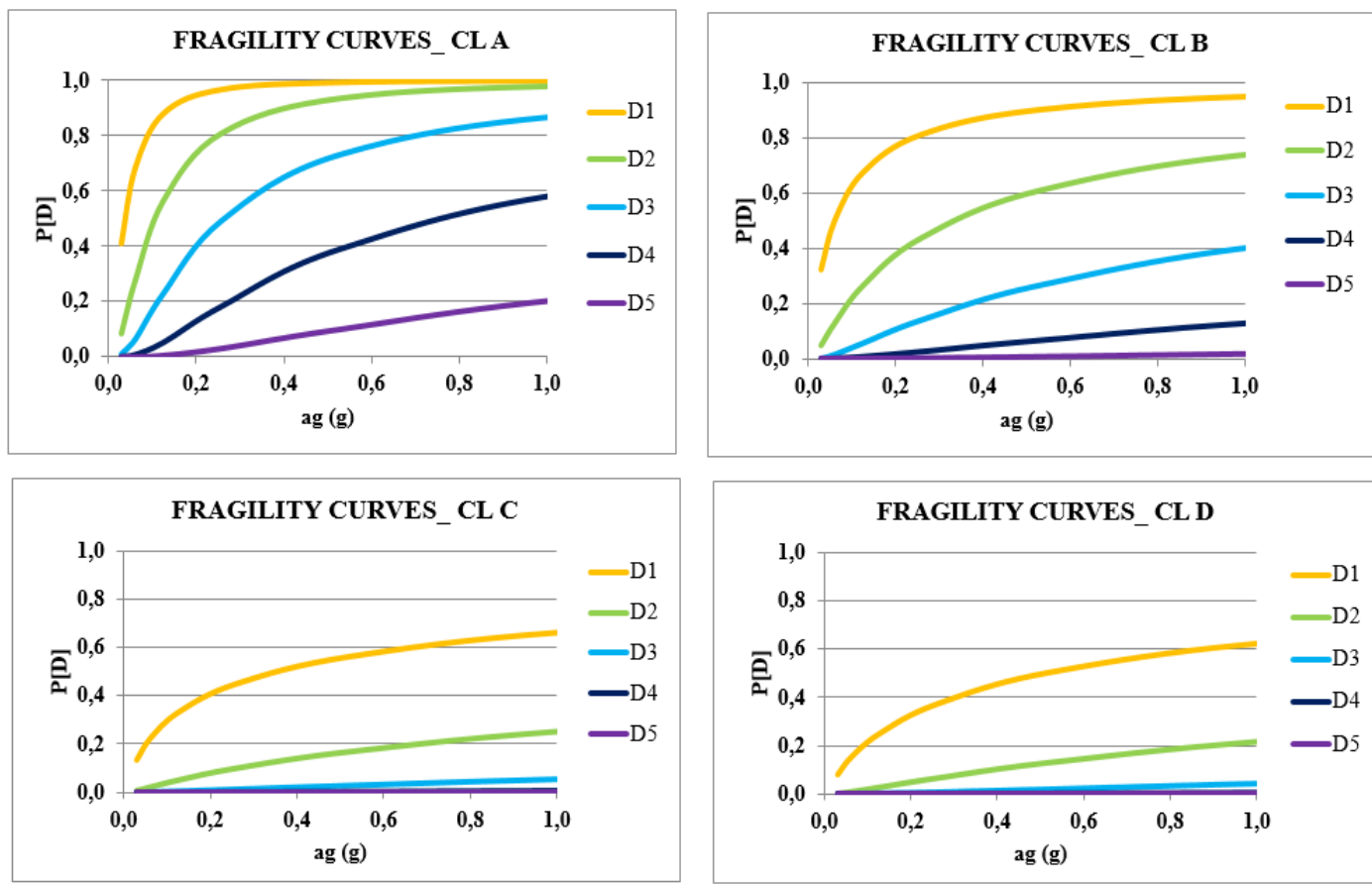

b)

Figure9. Fragility curves for the examined building typological classes on the basis of the first (a) and second (b) correlation laws given by Guagenti and Petrini.

The resilience is the capability of a social-ecological system to absorb or withstand perturbations such that the system maintains its structure and functions. It describes the degree of the system to selforganize after natural events. In the Engineering field, it is the ability to absorb or avoid damage without suffering the complete failure. In contrast, the term vulnerability indicate the inclination of structural units, persons or activities to undergo damage or modifications at an event occurrence. Therefore, it constitutes a fragility measure of individual buildings or infrastructure to absorb the impact of an event. With reference to this definition, the vulnerability of a system can be seen as the opposite of either its ability to absorb adverse disturbances or its resilience.

Therefore, seismic resilience curves (Figure 10) have been herein developed based on the fragility curves above reported based on the two different attenuation relationships of Guagenti and Petrini.

For the sake of example, with reference to the typological class $A$, the resilience probability to exceed a certain damage threshold tends to decrease with increasing of the buildings damage. 

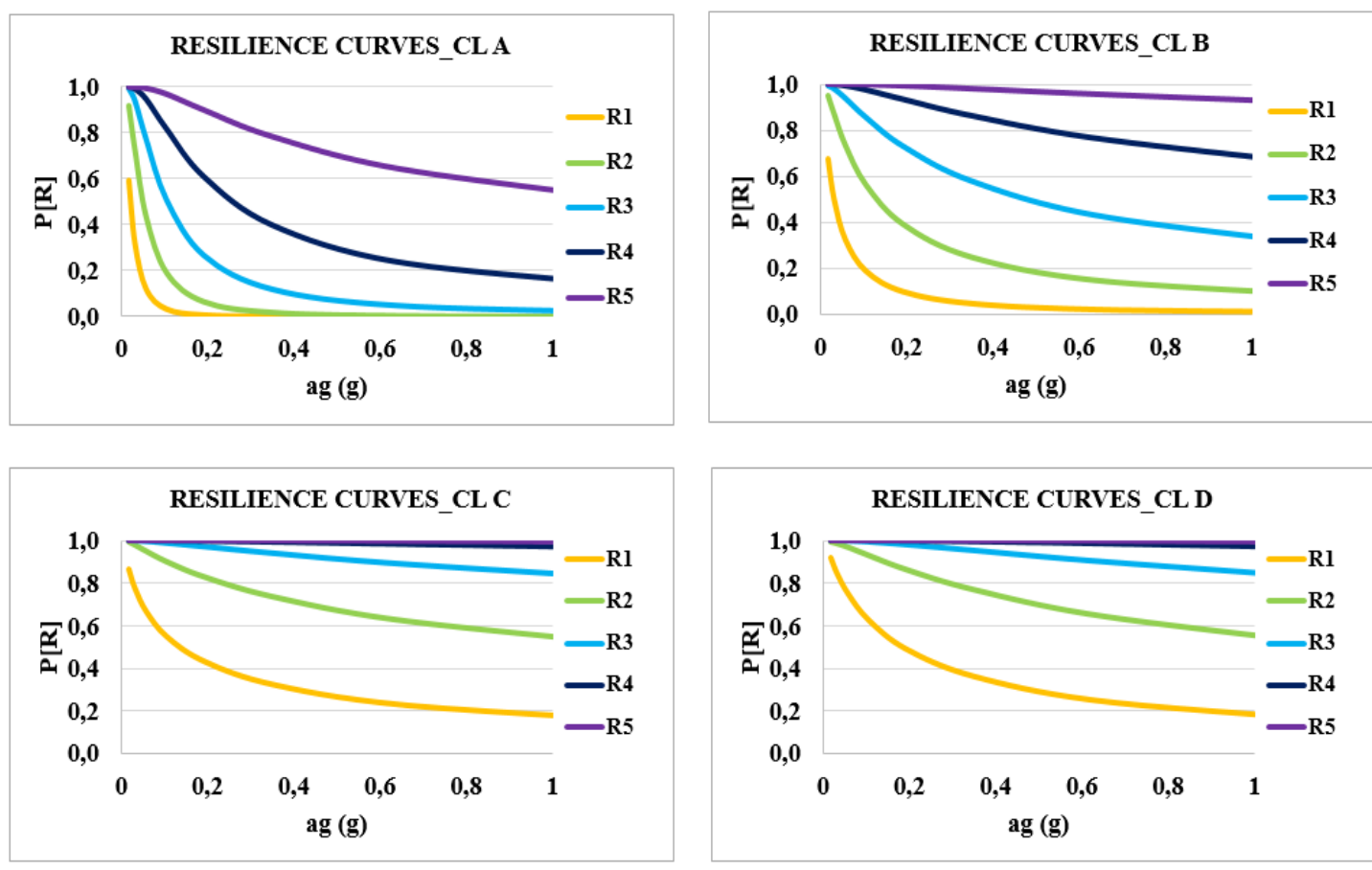

a)
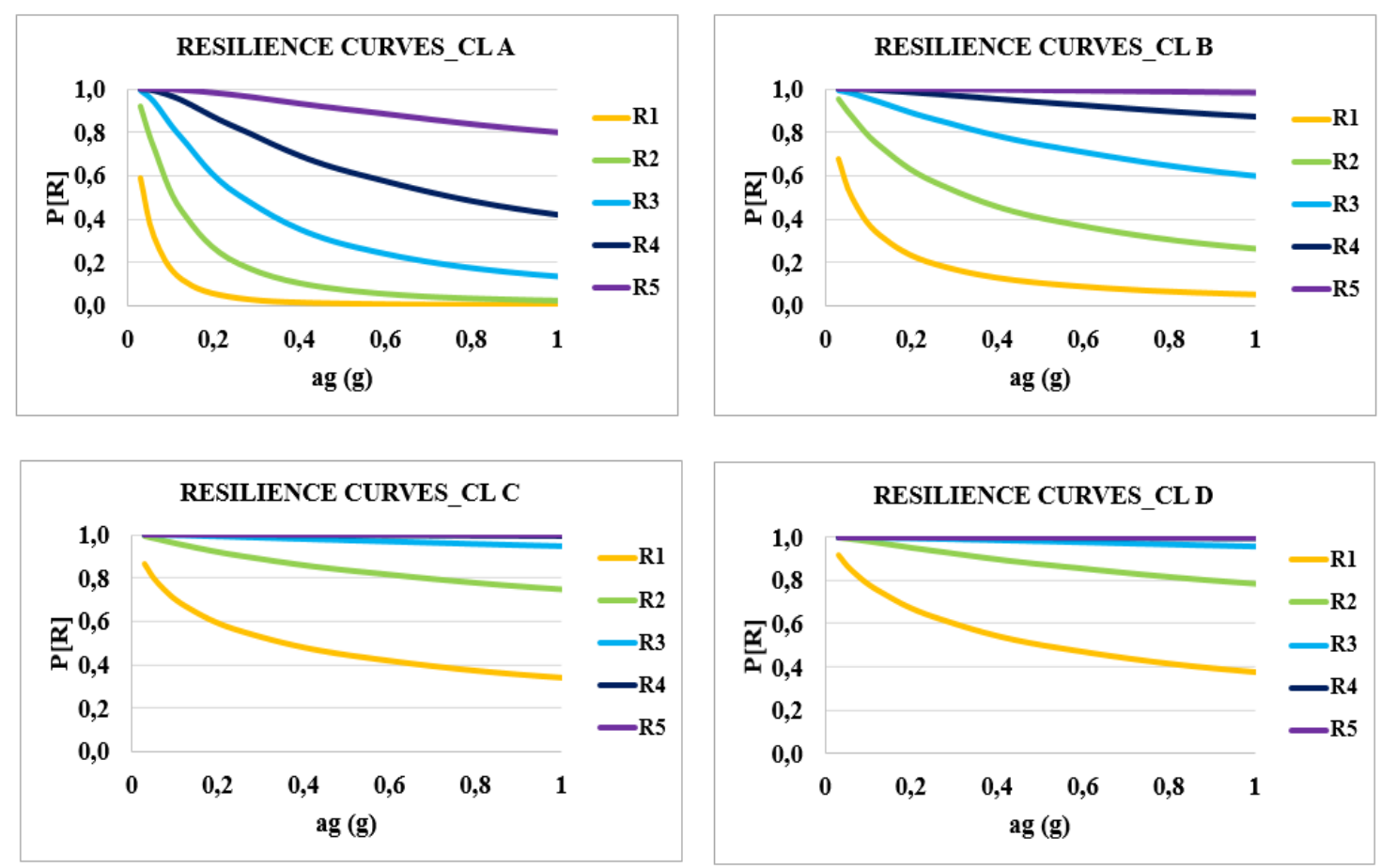

b)

Figure10. Resilience curves for inspected typological classes of buildings according to the first (a) and the second (b) correlation laws of Guagenti and Petrini.

In fact, for low seismic acceleration values $[0 \div 0.1 \mathrm{~g}]$, the urban class resilience probability has the highest values tending to one. It means that there is a probability of $100 \%$ that buildings do not suffer any damage and, therefore, that they are completely able to absorb the earthquake without altering their functionality.

Contrary, for a higher acceleration level, i.e. $0.4 \mathrm{~g}$, the resilience probability expected for the typological class tends to be reduced. In the case presented, if reference to the curve $R 4$ is made, $40 \%$ of buildings overcome the seismic event presenting moderate damage, while $60 \%$ of buildings should collapse, providing a zero residual resilience. Instead, for the typological class $D$, resilience probability tends to decrease with increasing damage, but with a lower slope than that of curves of other classes. This means that, for an acceleration of $0.4 \mathrm{~g}$ and with reference to the curve $R 4,99.9 \%$ of buildings can overcome the seismic event without presenting damages. 
Finally, it can also be observed that the second law proposed by Guagenti and Petrini provides the greatest resilience of the urban centre examined. In fact, for the sake of example, for the class type $D$ and for a ground acceleration of $0.2 \mathrm{~g}$, a resilience probability approximately equal to $69 \%$ for the resilient level $R l$ is achieved. Contrary, for the same building class and ground acceleration, the same curve given by the first law has provided a resilience probability equal to $49 \%$. As a consequence, the first law given by Guagenti and Petrini can be safely used with respect to the second one, because it underestimates the number of buildings able to withstand seismic actions without failure.

\section{Conclusions}

The study herein presented has allowed for the assessment of the seismic vulnerability, fragility and resilience of a construction sector within the historic centre of Marigliano. The territorial organization of resources for the preservation of the constructive heritage passes in fact from the knowledge of the seismic risk and, consequently, from its mitigation through the concept of the urban resilience. Through scenario analyses conducted, obtained by comparing the expected damage for different seismic intensities it is shown that, for modest seismic intensities, buildings show zero or very slight damage level $\left(0<\mu_{\mathrm{D}}<1\right)$, whereas for high intensities almost all buildings should collapse $\left(4<\mu_{\mathrm{D}}<5\right)$. On the other hand, the fragility analyses conducted have allowed to achieve and compare each other the resilience curves, able to analyse the propensity of an urban system to survive after the earthquake, achieved from application of two correlation laws given by Guagenti and Petrini between macro-seismic intensity and peak ground acceleration on the urban sector under examination. From these curves it is apparent that, when the damage increase, the urban sector tends to be less resilient, that is the resilience probability gradually tends to zero. For the sake of example, it can be noted that the expected value of the resilience probability for the typological class $A$ (the worst category of buildings inspected) to overcome a certain damage threshold tends to decrease with increasing propensity at the buildings damage. In particular, for low seismic acceleration values $[0 \div 0.1 \mathrm{~g}]$, the resilience probability of the urban system is highest and tends to unit value. This means that there is a probability of $100 \%$ that buildings do not suffer any damage and, therefore, the building class $A$ is able to absorb an earthquake without altering its functionality. Conversely, for high acceleration levels $[0.8 \mathrm{~g} \div 1 \mathrm{~g}]$, the resilience probability of the urban class $A$ is reduced. In this case, if $x$ is the percentage of buildings overcoming the seismic event with a fixed damage level, $1-x$ represents the percentage of buildings without any resilience.

Finally, it can also be observed that the second law proposed by Guagenti and Petrini provides the greatest resilience of the urban centre examined. In fact, provided a fixed ground acceleration for the different building classes and for several resilient levels considered, the curves generated on the basis of the second law of Guagenti and Petrini provides resilience probabilities greater than those achieved from curves gotten by applying the first attenuation law. As a consequence, the first law given by Guagenti and Petrini can be safely used with respect to the second one in generating resilience curves, because it underestimates the buildings number able to withstand seismic actions without failure.

\section{REFERENCES}

[1] Moroux P. and Le Brun, B., Presentation of RISK-UE project, Bulletin of Earthquake Engineering, 4 (4), 323-339 (2006).

[2] Formisano A.,Theoretical and Numerical Seismic Analysis of Masonry Building Aggregates: Case Studies in San PioDelleCamere (L'Aquila, Italy), Journal of Earthquake Engineering, 21 (2), 227-245 (2017).

[3] Maio R., Vicente R., Formisano A. and Varum H., Seismic vulnerability of building aggregates through hybrid and indirect assessment techniques, Bulletin of Earthquake Engineering, 13 (10), 2995-3014 (2015).

[4] Formisano A., Castaldo C. And Mazzolani F.M., Non-Linear analysis of masonry building compounds: A comparison of numerical and theoretical results, Civil-Comp Proceedings, 102 (2013).

[5] Lagomarsino S. and Giovinazzi S., Macroseismic and Mechanical Models for the Vulnerability assessment of current buildings, Bulletin of Earthquake Engineering, Special Issue "RISK-UE Project”, 4 (4), 415-443 (2006). 
[6] Giovinazzi S. and Lagomarsino S., A macroseismic method for the vulnerability assessment of buildings, Proceedings of the $13^{\text {th }}$ World Conference on Earthquake Engineering, Vancouver, Canada, Paper n. 896 (2004).

[7] Giovinazzi S., Balbi A. and Lagomarsino S., A vulnerability model for buildings in historical centres (in Italian), Proceedings of the $12^{\text {th }}$ Italian Conference on Earthquake Engineering (ANIDIS), Genoa, Italy (2004).

[8] Bernardini A., Giovinazzi S., Lagomarsino S. and Parodi S., Implicit Damage Probability Matrixes in the EMS-98 European Macroseismic Scale, Proceedings of the $12^{\text {th }}$ Italian Conference on Earthquake Engineering (ANIDIS), Pisa, Italy (2007).

[9] Bernardini A., Giovinazzi S., Lagomarsino S. and Parodi S., Vulnerability and damage assessment at a territorial scale according to a macroseismic approach coherent with EMS-98 European Macroseismic Scale, Proceedings of the $12^{\text {th }}$ Italian Conference on Earthquake Engineering (ANIDIS), Pisa, Italy (2007).

[10] Polese M., A double level approach for the seismic vulnerability evaluation of rc structures (in Italian), PhD thesis in Structures Engineering - XV cycle, University of Naples "Federico II" (2002).

[11] Guagenti E. and Petrini V., The case of old constructions: towards a new damage-intensity law (in Italian), Proceedings of the $4^{\text {th }}$ Italian Conference on Earthquake Engineering (ANIDIS), Milan, Italy, 145-153 (1989).

[12] Margottini C., Molin D. And Serva, L., Intensity versus ground motion: A new approach using Italian data, Engineering Geology, 33 (1), 45-58 (1992).

[13] Dolce M. and Zuccaro G., SAVE Project: Updated Tools for the Seismic Vulnerability Evaluation of the Italian Real Estate and of Urban Systems, $1^{\text {st } y e a r}$ report, National Group for Protection from earthquake (GNDT), Rome (2003).

[14] Holling C. S., Resilience and stability of ecological systems,Annu. Rev. Ecol. Syst., 4, 1-23 (1973).

[15] Walker B., Holling C. S., Carpenter S. R. And Kinzig A., Adaptability and Transformability in Social-Ecological Systems, Ecology and Society, 9 (2), Paper n. 5 (2004).

[16] Galderisi, A. andCeudech, A., Resilience and vulnerability of urban systems. A proposal for a seismic risk mitigation method" (in Italian),Proceedings of the XXIV Italian Conference on Regional Sciences, 1-20 (2003).

[17] Formisano A., Seismic behaviour and retrofitting of the PoggioPicenze historical centre damaged by the L'Aquila earthquake, Civil-Comp Proceedings, 99 (2012).

\section{AUTHORS' BIOGRAPHY}

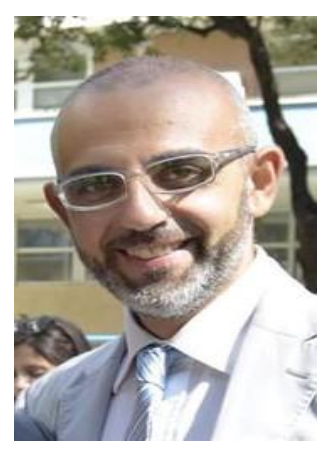

Antonio Formisano, is Born in Naples in 1977, June 23 ${ }^{\text {rd }}$, in 2003 he graduated cum laude in Building Engineering at the University of Naples 'Federico II', where in 2007 he gained his PhD in Construction Engineering. In the same year he became Assistant Professor of Structural Engineering at the Department of Structures for Engineering and Architecture of the aforementioned faculty, where actually he is Aggregate Professor of Structural Design. He is teacher of the Theory and Design of Steel Constructions course within the International Master "Emerging Technologies for Construction", teacher of the courses "Steel in Refurbishment" and "Aluminium Structures" within the International Master "Design of Steel" and teacher of the course "Rehabilitation and Maintenanc of Buildings" within the International Master "Sustainable Constructions under Natural Hazards and Catastrophic Events". He was and is involved in several national and international research projects. He is editorial board member and reviewer of numerous international journals. He is author of more than 200 scientific papers, published on national and international journals and conference proceedings, dealing with steel and aluminium structures, seismic and volcanic vulnerability of constructions, robustness and sustainability of structures. He received several awards and public acknowledgements for his scientific research activity. 


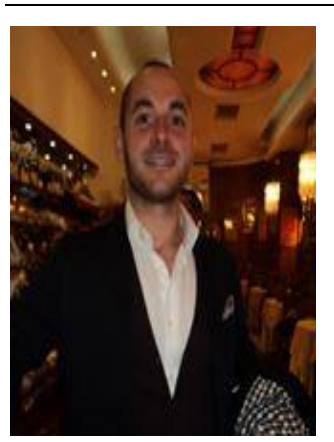

Nicola Chieffo, is Born in Naples on1985 May $20^{\text {th }}$, he graduated in Civil Engineering at the University of Naples "Federico II" with specialization in Structures and Geotechnics. From 2013 he continued his academic work as a collaborator of Prof. Ing. A. Formisano at the Department of Structures for Engineering and Architecture School of Polytechnic and Basic Sciences of the University of Naples in the field of "Seismic Vulnerability and Risk Analysis".

From 2017he is Ph.D student at the Universitatea Politehnica Timisoara in the field of "Seismic Vulnerability of Historical Buildings".

$\mathrm{He}$ is involved in numerous research projects and is author and co-author of scientific articles on seismic risk and urban resilience.

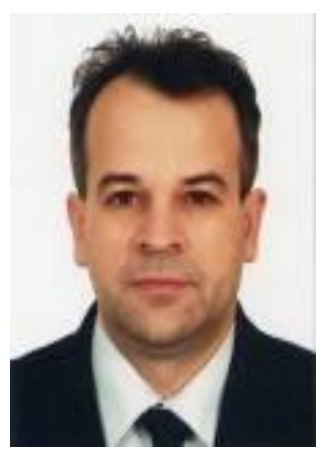

Prof. Habil. Eng. Marius Mosoarca, is a well known engineer in the field of complex architecture and restoration of historical buildings. Since 1994, we dedicated his work to civil engineering, graduating the Politehnica University of Timisora, Romania. In 2004, his PhD thesis „Contributions for calculation and composition of reinforced concrete structural walls, was recognised „cum laude,.. Since 2009, prof. Marius Mosoarca was a specialist of the National Heritage Minister, manager at S.C.H.I.Strut S.R.L., assistent and after that proffesor at Politehnica University of Timisoara and $\mathrm{PhD}$ coordinator.

His interest in teaching the others the balance between old and new is shown in the large amount of courses that he teaches, such as „Restoration and consolidation ,, , ,Structural design , , ,Antiseismic architecture, , ,,Structural aestetics, , ,Antiseismic urbanism,,, both for bachelor cycle and masteral one.

A very large number of articles and conference paper were wrote during last years, defining the preocupation of prof. Marius Mosoarca for developing new and innovative consolidation works in Romania and not only and permanently learning what this complex field has to offer.

Citation: Antonio Formisano et al. (2017) Fragility and Resilience Curves of an Urbanised sector in the District of Naples.. International Journal of Constructive Research in Civil Engineering, 3(2), pp.58-68.

Copyright: (C) 2017 Antonio Formisano, et al. This is an open-access article distributed under the terms of the Creative Commons Attribution License, which permits unrestricted use, distribution, and reproduction in any medium, provided the original author and source are credited 